\title{
POTENTIAL PROTECTIVE EFFECTS OF CHRYSIN ON EXPERIMENTALLY-INDUCED GASTROPATHY IN RATS
}

\author{
BY \\ Mina Y. George, Ahmed E. Abdel-razik, Marianne G. Tadros, Ebtehal E. Zaki \\ FROM \\ Department of Pharmacology \& Toxicology, Faculty of Pharmacy, Ain Shams \\ University, Cairo, Egypt
}

\begin{abstract}
Gastric ulcer is one of the major gastrointestinal disorders affecting people worldwide. Despite medical advances, management of gastric ulcer and its complications remains a challenge facing medicine nowadays. In addition, currently available medicines exhibited limited efficacy and several side effects. Chrysin is a naturally occurring flavonoid with anti-oxidant and anti-inflammatory properties. Thus, it may play a pivotal part in management of gastric ulcer. The current research suggested that chrysin possesses a potential protective effect against indomethacininduced gastric ulcer via the underlying anti-oxidant and anti-inflammatory mechanisms. Chrysin was administered to spargue-Dawly rats (200-220 gm) at three different doses; 25, 50 and $100 \mathrm{mg} / \mathrm{kg}$, single oral dose (S.O.D) compared to omeprazole given at a dose of $30 \mathrm{mg} / \mathrm{kg}$, S.O.D. Indomethacin was administered at a dose of $48 \mathrm{mg} / \mathrm{kg}$, S.O.D. As indicators of oxidative stress, indomethacin treatment caused significant reduction in catalase enzyme activity. Chrysin pretreatment significally attenuated indomethacin-induced oxidative injury. Additionally, indomethacin provoked inflammatory responses via increasing the level of tumor necrosis factor-a while chrysin pretreatment significally inhibited those inflammatory responses. Furthermore, indomethacin was found to increase acidity in stomach leading to gastric mucosal injury while chrysin pretreatment lead to returnin acidity nearly to normal reducing gastric mucoal injury. Collectively, these findings indicate that chrysin possesses a potential protective effect against indomethacin-induced gastric ulcer via suppressing acidity, oxidative stress and inflammation.
\end{abstract}

Keywords: Chrysin; indomethacin-induced gastric ulcer; antioxidant; antiinflammatory; acidity.

\section{Introduction}

Stomach tissue is formed of several layers which are mucosal layer, submucosal layer, serosa, muscularis mucosa and finally smooth muscle. Gastric ulcer is one of the major gastrointestinal disorders affecting people worldwide. It could develop due to the disbalance of some endogenous aggressive factors (gastric acid, pepsin, leukotrienes) and gastroprotective factors, such as mucus, bicarbonate, prostaglandins, mucosal blood flow, and some growth factors (Mota et al., 2009).

Gastric ulcer is the most predominant of the gastrointestinal diseases with a worldwide prevalence of about $40 \%$ in the developed countries and $80 \%$ in the developing countries (Malfertheiner et al., 2009). Each year gastric ulcer affects 4 
million people around the world. Complications as bleeding, perforation and gastric outlet obstruction are encountered in $10 \%-20 \%$ of these patients. Perforated gastric ulcer is a quite rare, but life threatening disease and the mortality varies from $10 \%-40 \%$ (Zelickson et al., 2011).

There are several models that are used to evaluate antiulcer medicines. However, the choice of a suitable model has proven to be difficult as each model has significant advantages as well as disadvantages (Choi et al., 2009).

Inflammation -normal physiologic defending body process- plays a pivotal part in gastric ulcer disease (Musumba et al., 2012). The inflammatory response involves the sequential activation of signaling molecules such as prostaglandins, tumor necrosis factor- $\alpha(\mathrm{TNF}-\alpha)$, Interleukins, inducible transcription factor nuclear factor- $\kappa \mathrm{B}$ (NF$\kappa \mathrm{B})$, intracellular adhesion molecule-1 (ICAM-1), vascular cell adhesion molecule 1 (VCAM-1) and E-selectins. NF- $\mathrm{BB}$ activation through phosphorylation and subsequent proteolytic degradation of $\mathrm{I} \kappa \mathrm{B}$ through the action of the I $\mathrm{KB}$ kinase plays a central role in inflammatory processes in gastric ulcers (Tak and Firestein, 2001).

NSAIDs are utilized in treatment of pain and inflammation in rheumatic disorders and osteoarthritis (Pal et al., 2010). On the other side, they were reported to cause severe gastrointestinal complications like gastric mucosal bleeding, decreased gastric mucosal blood flow and induced mucosal cell apoptosis (Bindu et al., 2013). Amongst the NSAIDs, indomethacin has the highest ulcer-inducing potential to humans (Henry et al., 1993).

Being a known inducer of reactive oxygen species (ROS) and reactive nitrogen species (RNS) in animal models, indomethacin contributes to mucosal injury (Utsumi et al., 2006). This oxidative stress is associated with the uncoupling of mitochondrial respiration, formation of the mitochondrial permeability transition pore, mitochondrial dysfunction and generation of mitochondrial oxidative stress (Pal et al., 2010). Indomethacin promotes neutrophil infiltration that initiates leukocyte-endothelial cell (EC) interaction via the intermediacy of various selectins and cellular adhesion molecules (CAMs) (Wallace et al., 1990). To get rid of those harmful ROS and RNS, several enzymatic and non-enzymatic antioxidants in gastric cells are stimulated such as catalase (CAT), superoxide dismutase (SOD), glutathione peroxidase (GSHP) and endogenous reduced glutathione (GSH) but unfortunately excessive generation of ROS increases lipid peroxides such as MDA and depletes these antioxidant enzymes (Cadirci et al., 2007; Liu et al., 2012).

Flavonoids consist of a large group of polyphenolic compounds having a benzo$\square$-pyrone structure and are ubiquitously present in plants (Mahomood et al., 2005). Available reports tend to show that secondary metabolites of phenolic nature including flavonoids are responsible for the variety of pharmacological activities (Pandey, 2007). Flavonoids possess many biological properties such as: antioxidant (Woo et al., 2007), anti-ulcer (Mota et al., 2009), hepatoprotective (Tapas et al., 2008), antibacterial (Mishra et al., 2013) and anticancer activities (Duthie et al., 2000).

Recently, flavonoids are considered as a target for researchers owing to their promising powerful antioxidant properties that protect the human body from free radicals via hydrogen donating (Danish et al., 2014). 
Chrysin (5,7-dihydroxyflavone) belongs to this category which is found in bee propolis, honey and various plants (Barbaric et al., 2011). It is produced during the secondary metabolism of plants as the first line of defense against ultraviolet irradiation, oxygen radical production, and/or invading organisms (Kumar and Pandey, 2013). It has multiple biological activities such as antioxidant, anti-inflammatory, anti-apoptotic, anti-cancer (Sultana et al., 2012), anti-atherosclerosis, hypolipidemic, and hypoglycemic effects (Xiao et al., 2011).

Therefore, the aim of the current study was to investigate the potential protective effects of the natural product chrysin against indomethacin-induced gastric ulcer as well as the possible underlying anti-oxidant and anti-inflammatory mechanisms compared to omeprazole.

\section{Materials and methods}

\section{Drugs and chemicals}

Chrysin, Dimethylsulfoxide (DMSO) and Carboxymethyl-cellulose (CMC) were purchased from Sigma Chemical Co. (St. Louis, MO, USA). Indomethacin was purchased from Nile Co. for Pharmaceutical and Chemical Industries (Egypt). Gum acacia was purchased from El-Nasr Chemical Co. (Egypt). Omeprazole was purchased as Gastroloc $®$ from Sigma pharmaceutical industries S.A.E. (Egypt). All other chemicals were of the highest purity grade commercially available.

\section{Animals}

Male spargue-Dawly rats (200-220 gm) were purchased from Nile Co. for Pharmaceutical and Chemical Industries, Cairo, Egypt. Handling and experimentation was conducted in accordance with the international ethical guidelines concerning the care and use of laboratory animals (Ain Shams University, Egypt). Rats were housed in an air-conditioned atmosphere, at a temperature of $25^{\circ} \mathrm{C}$ with alternatively $12 \mathrm{~h}$ light and dark cycles and were reared on a balanced laboratory diet and given tap water ad libitum. Before ulcer induction, the animals were deprived of food for $24 \mathrm{~h}$ with free access to tap water.

\section{Experimental design}

Rats were randomly assigned to seven groups (ten animals each) and treated as follows: Group 1 (negative control group) received single oral dose of mixture of DMSO and corn oil (1:9) (chrysin vehicle) followed one hour later by a single oral dose of $2 \%$ gum acacia in distilled water (indomethacin vehicle) (Yadav et al., 2012). Group 2 received single oral dose of indomethacin at a dose of $48 \mathrm{mg} / \mathrm{kg}$ (Eun-Kyung et al., 2009) followed one hour later by a single oral dose of DMSO and corn oil mixture (1:9). Group 3 was pretreated with a single oral dose of omeprazole at a dose of 30 $\mathrm{mg} / \mathrm{kg}$ (Papiya and Kailash, 2014) followed one hour later by a single oral dose of indomethacin $(48 \mathrm{mg} / \mathrm{kg})$. Groups 4, 5 and 6 were pretreated with a single oral dose of chrysin at doses of 25,50 and $100 \mathrm{mg} / \mathrm{kg}$, respectively. One hour later, groups (4-6) received single oral dose of indomethacin $(48 \mathrm{mg} / \mathrm{kg}$ ). The last group (Group 7) received single oral dose of chrysin only at its highest dose $100 \mathrm{mg} / \mathrm{kg}$ followed one hour later by single oral dose of $2 \%$ gum acacia in distilled water. Rats were sacrificed $12 \mathrm{~h}$ after treatment, their stomachs were dissected out and gastric juice was collected 
from each for acidity determination. The remainder of each stomach was homogenized in potassium phosphate buffer $(\mathrm{pH} 7.5)$ for further biochemical analysis.

\section{Determination of acidity}

The gastric juice was collected and its volume was measured. Gastric content was centrifuged, diluted ( $1 \mathrm{ml}$ diluted with $9 \mathrm{ml}$ of distilled water) and $0.2 \mathrm{ml}$ of clear supernatant was titrated against $0.01 \mathrm{~N} \mathrm{NaOH}$, using phenol phethaline (phph) till first persistent pink color. Volume of $\mathrm{NaOH}$ corresponds to total acidity (Grossman., 1963). Results were expressed as milliequivalents per liter $(\mathrm{mEq} / \mathrm{L})$. The titrable acidity was calculated as follows:

$$
\text { Titratable acidity }(\mathrm{mEq} / \mathrm{L})=\frac{\mathrm{V} 1 \times 1000}{\mathrm{~V} 2 \times 100}
$$

Where:

$$
\begin{aligned}
& \mathrm{V} 1=\text { Volume }(\mathrm{L}) \text { of } 0.01 \mathrm{~N} \mathrm{NaOH} \text { used for titration. } \\
& \mathrm{V} 2=\text { Volume }(\mathrm{L}) \text { of gastric secretion taken for titration }
\end{aligned}
$$

\section{Histopathology}

Sections from gastric tissues were fixed in $10 \%$ neutral buffered formalin and processed for paraffin sections of $4-\mu \mathrm{m}$ thickness by slide microtome. Sections were collected on glass slides, deparaffinized, then stained by hematoxylin and eosin stain for examination through the light electric microscope (Banchroft et al., 1996).

\section{Protocol for biochemical studies}

Stomachs from different groups were homogenized in neutral buffered saline under cold conditions then the homogenate was used for assessment of the following biochemical parameters.

\section{Assessment of antioxidant Catalase enzyme activity}

Assessment of catalase (CAT) enzyme activity in stomach homogenate was done using kits provided by Biodiagnostics, Giza, Egypt. CAT activity was estimated colorimetrically, where each unit of CAT decomposes $1 \mu \mathrm{M}$ of hydrogenperoxide (H2O2) per min at $25 \mathrm{C}$ and $\mathrm{pH} 7.0$ according to the method of Aebi (1984). CAT reacts with a known quantity of $\mathrm{H} 2 \mathrm{O} 2$. The reaction is stopped after exactly 1 min with CAT inhibitor. In the presence of peroxidase, remaining $\mathrm{H} 2 \mathrm{O} 2$ reacts with 3,5-dichloro2-hydroxybenzenesulfonic acid and 4-aminophenazone to form a chromophore with a color intensity inversely proportional to the amount of CAT in the original sample. Enzyme activities were expressed as unit/mg protein.

\section{Assessment of Tumor necrosis factor- $\alpha$ (TNF- $\alpha)$}

Gastric TNF- $\alpha$ level in stomach homogenate was assessed. Determination of TNF- $\alpha$ was performed using commercial AviBion ELISA kit (Catalogue No.: FIN00790, Helsinki, FINLAND) according to the manufacturer's instructions. The quantities of rat TNF- $\alpha$ was expressed as $\mathrm{pg} / \mathrm{mg}$ protein. 


\section{Statistical analysis}

Data are presented as mean \pm SD. Multiple comparisons were performed using one-way ANOVA followed by Tuckey post hoc test. The 0.05 level of probability was used as the criterion for significance. All statistical analyses were performed using Instat software version 3. Graphs were sketched using GraphPad Prism software version 5 (GraphPad Software, Inc., La Jolla, CA, USA).

\section{Results}

\section{Acidity determination}

Indomethacin-treated group showed significant increase in acid production $(26.667 \pm 4.773)$ relative to control group while all pretreated groups either with omeprazole or chrysin showed significant reduction in acidity relative to indomethacin treated group. Otherwise, both pretreated groups with chrysin 25 and $50 \mathrm{mg} / \mathrm{kg}$ showed significant increase in acidity relative to control group (Fig. 1)

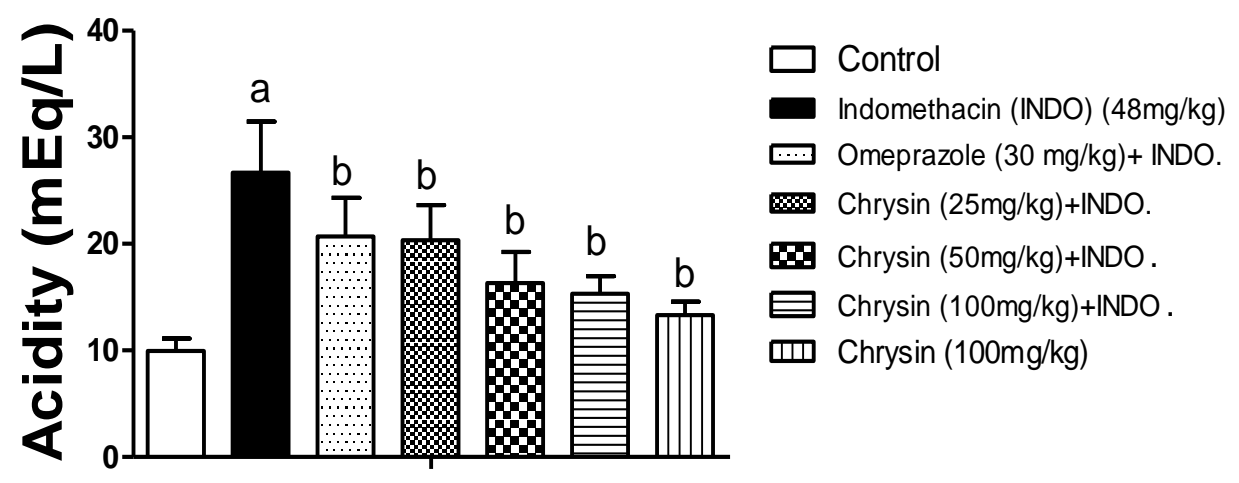

\section{Fig. (1) Effect of chrysin pretreatment on gastric acid secretion.}

Data are expressed as mean \pm SD. (a) significally different from control group and (b) significally different from indomethacin-treated group at $\mathrm{P}<0.05$ using one way ANOVA followed by Tuckey as a post-hoc test.

\section{Histological examination}

Gastric tissues from control group showed normal histological structure of the mucosa, submucosa, muscularis mucosa and serosa (2A). Group of Indomethacintreated rats showed destructed lyning epithelium of mucosal layer leading to focal ulceration with necrosis as well as inflammatory cells infilteration in the mucosal layer while the underneath submucosa showed focal inflammatory cell infilteration (2B). Rest of groups either pretreated with omeprazole $(30 \mathrm{mg} / \mathrm{kg})$ or chrysin at its different doses used $(25,50$ and $100 \mathrm{mg} / \mathrm{kg})$ showed no histopathological alterations as seen in $(2 \mathrm{C}$, $2 \mathrm{D}, 2 \mathrm{E}$ and $2 \mathrm{~F}$ ). Also the group of rats treated with chrysin only showed normal histological structure of mucosa, submucosa, muscularis mucosa and serosa (2G). 

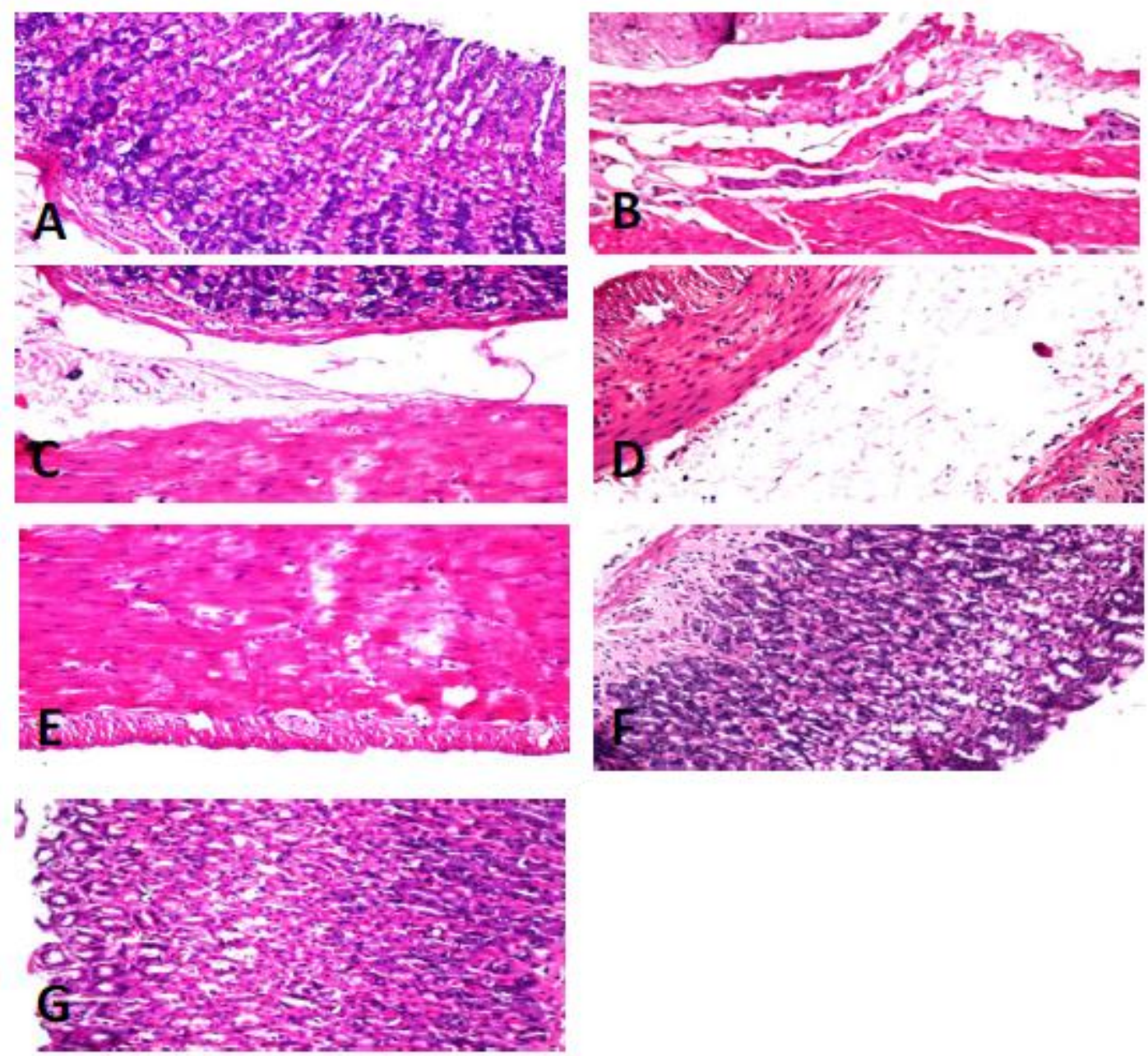

Fig. (2) Effect of chrysin pretreatment on histology of gastric tissue.

Photomicrographs of haematoxylin and eosin stained sections of stomach from control group (A), indomethacin-treated group (B), omeprazole-pretreated group (30 mg/kg) (C), chrysin-pretreated groups $(25,50$ and $100 \mathrm{mg} / \mathrm{kg}$ ) (D, E and F, respectively) and chrysin alone-treated group $(100 \mathrm{mg} / \mathrm{kg})(\mathrm{G})$ with 40x magnification power.

\subsection{Anti-oxidant catalase (CAT) enzyme activity}

Indomethacin induced a significant decrease in the stomach antioxidant enzyme activities of CAT compared to the control levels. Pretreatment with omeprazole significantly increased CAT activity compared to indomethacin-treated group. Rats pretreated with chrysin at $25 \mathrm{mg} / \mathrm{kg}$ showed a significant increase in CAT activity compared to indomethacin-treated group. Rats pretreated with either chrysin $50 \mathrm{mg} / \mathrm{kg}$ or $100 \mathrm{mg} / \mathrm{kg}$ showed significant increase in CAT activity compared to indomethacintreated group. Chrysin alone-treated group showed no significant difference compared to control group (Fig. 3). 


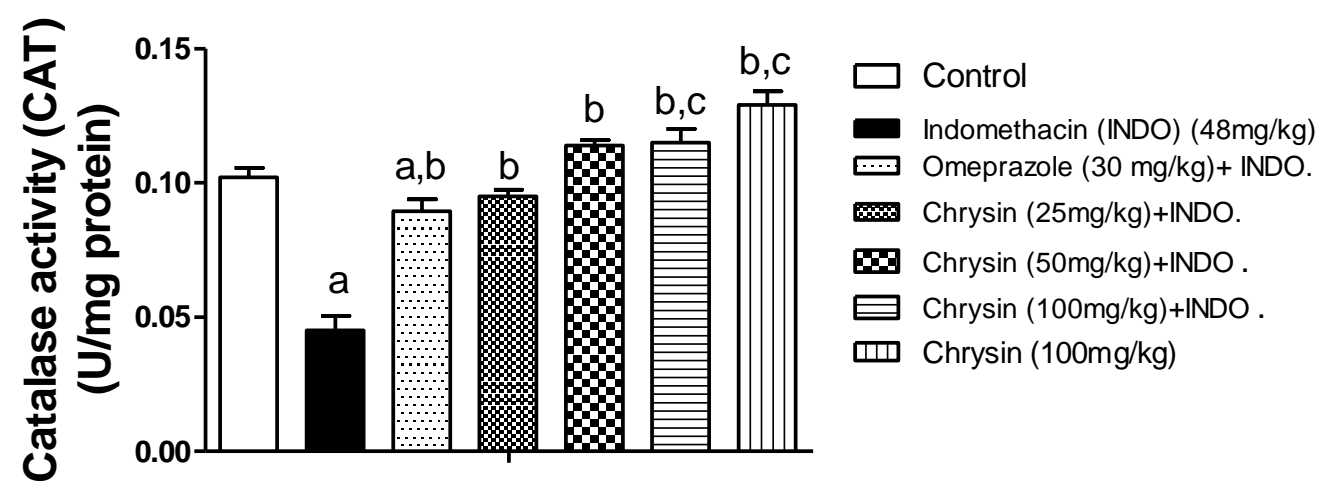

Fig. (3) Effect of chrysin pretreatment on catalase enzyme activity

Data are presented as mean \pm SD $(n=8)$ where:

(a) $\mathrm{P}<0.05$ statistically significant from corresponding control group.

(b) $\mathrm{P}<0.05$ statistically significant from indomethacin-treated group.

(c) $\mathrm{P}<0.05$ statistically significant from omeprazole-pretreated group.

One way analysis of variance (ANOVA) was used followed by Tuckey as a post-hoc test.

\section{Infalmmatory marker (TNF- $\alpha)$}

Indomethacin-induced proinflammatory response was evidenced by the significant increase in TNF- $\alpha$ in the gastric tissues compared to the control group. Pretreatment with omeprazole $(30 \mathrm{mg} / \mathrm{kg})$ or chrsyin at all its doses $(25 \mathrm{mg} / \mathrm{kg}, 50$ $\mathrm{mg} / \mathrm{kg}$ and $100 \mathrm{mg} / \mathrm{kg}$ ) exhibited anti-inflammatory effects by significantly reducing TNF- $\alpha$ level compared to indomethacin-treated group. Chrysin alone treatment didn't show any significant effect on stomach TNF- $\alpha$ level compared to the control group (Fig. 4).

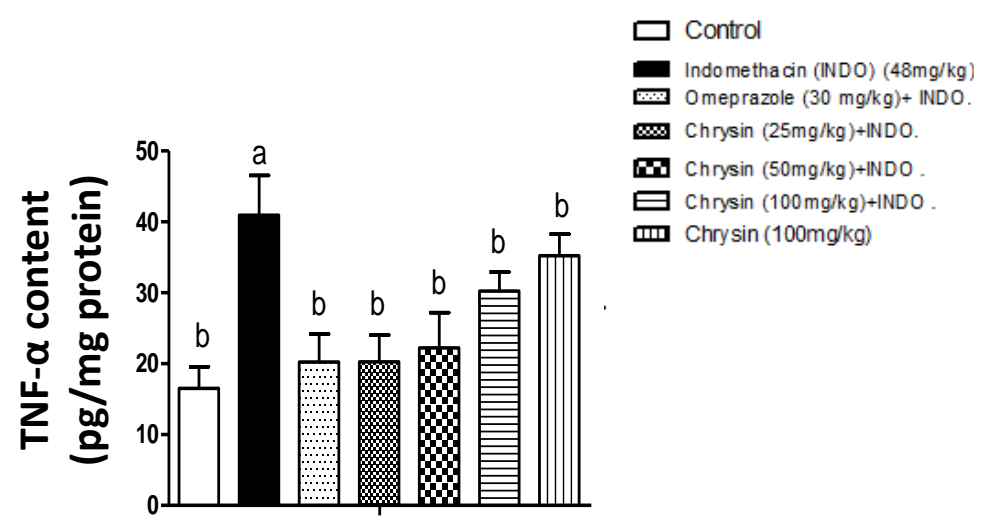

Fig. (4) Effect of chrysin pretreatment on TNF- $\alpha$ level.

Data are presented as mean $\pm \mathrm{SD}(\mathrm{n}=8)$ where:

(a) $\mathrm{P}<0.05$ statistically significant from corresponding control group.

(b) $\mathrm{P}<0.05$ statistically significant from indomethacin-treated group.

One way analysis of variance (ANOVA) was used followed by Tuckey as a post-hoc test 


\section{Discussion}

The objective of the present study was to investigate the potential protective effects of chrysin on indomethacin-induced gastric ulcer in rats through its anti-oxidant and anti-inflammatory properties. Using the above discussed model, chrysin was used with three different doses 25,50 and $100 \mathrm{mg} / \mathrm{kg}$ to study the possible underlying mechanisms compared to omeprazole.

Omeprazole was used as the positive control drug in this study as it is widely used to protect the gastric mucosa from ulceration. Several studies that have involved gastroprotective activities have used omeprazole as the positive control (Ketuly et al., 2013; Sidahmed et al., 2013). Omeprazole is a proton pump inhibitor that decreases the production of gastric acid for treatment of diseases associated with gastric acid secretion (Shin and sachs, 2008). In addition, omeprazole is also very effective in acid-dependent ulcer models (Shahram et al., 2013).

Moreover, gastric ulcer also results from increased level of reactive oxygen species (ROS) such as superoxide anions, hydrogen peroxide and hydroxyl radicals. These radicals in turn lead to increased gastric oxidative stress that has an essential role in gastric hemorrhage and ulcer formation (Repetto and Llesuy, 2002). In our study, increased oxidative damage was observed in indomethacin-treated rats because indomethacin was reported to distinctly attenuate the antioxidant enzyme activity of catalase in the rat gastric mucosa (Kim et al., 2011). On the other hand, chrysin pretreatment effectively reduced the extent of indomethacin-induced oxidative stress whereas it has potent free radical scavenging properties which are associated with the hydroxyl substitution in the fifth and seventh positions that directly sequestrates free radicals (Sathiavelu et al., 2009).

Beside its direct deleterious effect, it was found that oxidative stress induced by indomethacin can induce inflammatory responses via activation of redox sensitive transcription factors such as NF- $\kappa \mathrm{B}$. NF- $\kappa \mathrm{B}$ is a transcription factor consisting of $\mathrm{p} 65$ and p50 subunits of Rel protein family that regulates the host inflammatory and immune responses (Bindu et al., 2013). Upon occurrence of different extracellular stimuli such as infection, inflammation and oxidative stress, $\mathrm{NF}-\kappa \mathrm{B}$ is transported from the cytoplasm to the nucleus, where it binds to specific target genes to induce their transcription (Hoffmann et al., 2006). El-sharkawy and Mann (2007) reported that NF$\kappa \mathrm{B}$ as a critical mediator of inflammatory response, regulates the expression of certain proinflammatory mediators such as TNF- $\alpha$. In our study, chrysin decreased TNF- $\alpha$ level. These findings suggest that chrysin can attenuate inflammation via the inhibition of NF- $\kappa \mathrm{B}$ and downstream pro-inflammatory cytokines decreasing also level of TNF- $\alpha$. These results are in agreement with previous recent report that have reported about chrysin as a potential inhibitor of $\mathrm{NF}-\kappa \mathrm{B}$ and can diminish the downstream inflammatory cytokines production (Dou et al., 2013).

Furthermore, chrysin was found to decrease acidity induced by indomethacin for the first time in experimental studies. Increased acidity lead to gastric mucosal injury and bleeding may develops. Chrysin significantly hindered indomethacin acidity in a dose-related manner. Thus, chrysin could protect against gastric mucosal injury and could be an alternative safe solution for protection against gastric ulcer to be further investigated clinically. 


\section{REFRENCES}

Aebi H., 1984. Catalase invitro. Methods Enzymol. 105, 121-126.

Banchroft , J.D.; Stevens , A. And Turner , D.R. (1996). THEORY AND PRACTICE OF HISTOLOGICAL TECHNIQUES. Fourth Ed. Churchil Living stone, New York, London, San Francisco, Tokyo.

Barbaric, M., Miskovic, K., Bojic, M., Loncar, M.B., Smolcic-Bubalo, A., Debeljak, Z., Medic-Saric, M., 2011. Chemical composition of the ethanolic propolis extracts and its effect on HeLa cells. J. ethanopharmacol. 135, 772-778.

Bindu S., Mazumder S., Dey S., Pal C., Goyal M., Alam A., Iqbal MS., Sarkar S., Azhar Siddiqui A., Banerjee C., Bandyopadhyay U (2013). Non-steroidal anti-inflammatory drug induces proinflammatory damage in gastric mucosa through NF-kappa $\beta$ activation and neutrophil infiltration: anti-inflammatory role of heme oxygenase-1 against non-steroidal anti-inflammatory drug, Free Radic. Biol. Med. 65:456-467.

Cadirci S., Halis A., Hulya H., Zekai O., 2007. Effects of Onosma armeniacum root extract on ethanol-induced oxidative stress in stomach tissue of rats. ChemicoBiological Interactions. 170:40-48.

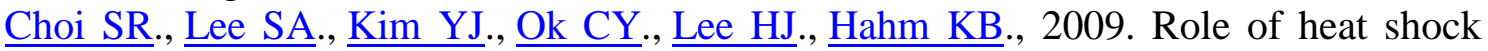
proteins in gastric inflammation and ulcer healing. J Physiol Pharmacol.7:5-17.

Danish A., Vikas K., Manju S., Amita V(2014). Target guided isolation, in vitro antidiabetic, antioxidant activity and molecular docking studies of some flavonoids from Albizzia Lebbeck Benth. Bark. ISCMR, 14:155 DOI: $10.1186 / 1472-6882-14-155$.

Dou W., Zhang J., Zhang E., Sun A., Ding L., Chou G., Wang Z., Mani S., 2013. Chrysin ameliorates chemically induced colitis in the mouse through modulation of a PXR/NF- $\mathrm{BB}$ signaling pathway. J. pharmacol. Exp. Therapeut. 345, 473482.

Duthie G., Duthie J., Kyle A., 2000. Plant polyphenols in cancer and heart disease: implications as nutritional antioxidants. Nutrition research reviews 13, 79-106.

Elsharkawy AM., Mann DA., 2007. Nuclear factor-kappa $\beta$ and the hepatic inflammation-fibrosis-cancer axis. J. Hepat. 46, 590-597.

Eun Kyung Shin, Hyuck-Se Kwon, Yoon Hee Kim, Hyun-Kyung Shin, Jin-Kyung Kim, (2009) Chrysin, a natural flavone, improves murine inflammatory bowel diseases, Biochemical and Biophysical Research Communications, 381 502-507.

Grossman, M.I., 1963. Physiology for physician. Am. Physiol. Soc. 1, 1-5.

Henry, D., Robertson, J (1993). Non-steroidal anti-inflammatory drugs and peptic ulcer hospitalization rates in New South Wales. Gastroenterology; 104: 10831091.

Hoffmann A., Natoli G., Ghosh G., 2006. Transcriptional regulation via the NF-k $\beta$ signaling module. Oncogene 25,6706-6716.

Ketuly KA., Hadi AHA., Golbabapour S., Hajrezaie M., Hassandarvish P., et al. (2013). Acute toxicity and gastroprotection studies with a newly synthesized steroid. PLoS One 8:1-9.

Kim JH., Kim BW., Kwon HJ., Nam SW., 2011. Curative effect of selenium against indomethacin-induced gastric ulcers in rats, J. Microbiol. Biotechnol. 21:400404. 
Kumar, S., Pandey, A.K., 2013. Chemistry and biological activities of flavonoids: an overview. Sci.World J., 162750.

Liu D., Xu Y (2011). p53, Oxidative Stress, and Aging. Antioxidants \& redox signaling,. 15:1669-1678.

Mahomoodally, M. F., Gurib-Fakim, A., Subratty, A. H., 2005. Antimicrobial activities and phytochemical profiles of endemic medicinal plants of Mauritius. Pharma. biol. 43, 237-242.

Malfertheiner P., Chan FK., McColl KE (2009). "Peptic ulcer disease," The Lancet, vol. 374, no. 9699, pp. 1449-1461.

Mishra A., Sharma K., Kumar S., Saxena A., Pandey A (2013). Bauhinia variegata leaf extracts exhibit considerable antibacterial, antioxidant, and anticancer activities. BioMed Research International. 23:78-83

Mota, K., Dias, G., Pinto, M., Ferreira, A., Brito, A., Lima, C., Filho, J. and Batista, L (2009). Flavonoids with Gastroprotective Activity. Molecules. 14: 979-1012.

Musumba C, Jorgensen A, Sutton L, et al (2012). The relative contribution of NSAIDs and Helicobacter pylori to the aetiology of endoscopically-diagnosed peptic ulcer disease: observations from a tertiary referral hospital in the UK between 2005 and 2010. Aliment Pharmacol Ther. 36(1): 48-56.

Pal C., Bindu S., Dey S., Alam A., Goyal M., Iqbal MS., Maity P., Adhikari SS., Bandyopadhyay U (2010). Gallic acid prevents non-steroidal anti-inflammatory drug-induced gastropathy in rat by blocking oxidative stress and apoptosis. Free Radic. Biol. Med. 49:258-267.

Papiya B., Kailash S., 2014. Ulcer protective potential of standardized hesperidin, a citrus flavonoid isolated from Citrus sinensis, Rev Bras pharma; 24: 330-340.

Repetto M., Llesuy S., (2002). Antioxidant properties of natural compounds used in popular medicine for gastric ulcers. Brazilian Journal of Medical and Biological Research 35: 523-534.

Sathiavelu, J., Senapathy, G.J., Devaraj, R., Namasivayam, N., 2009. Hepatoprotective effect of chrysin on prooxidant-antioxidant status during ethanol-induced toxicity in female albino rats. J. pharma. Pharmacol. 61, 809817.

Shahram G., Maryam H.,Pouya H., Nazia A., et al (2013). Acute Toxicity and Gastroprotective Role of $M$. pruriens in Ethanol-Induced Gastric Mucosal Injuries in Rats. Biomed Res Int. 54:21-32.

Shin J., Sachs G (2008). Pharmacology of Proton Pump Inhibitors. Curr Gastroenterol Rep. 10(6): 528-534.

Sidahmed H., Abdelwahab SI., Mohan S., Abdulla MA., Mohamed Elhassan Taha M., et al. (2013). $\alpha$-Mangostin from Cratoxylum arborescens (Vahl) Blume Demonstrates Anti-Ulcerogenic Property: A mechanistic Study. Evidence-Based Complementary and Alternative Medicine.

Sultana, S., Verma, K., Khan, R., 2012. Nephroprotective efficacy of chrysin against cisplatin-induced toxicity via attenuation of oxidative stress. J. pharma. Pharmacol. 64, 872-881.

Tak, P., Firestein, GS (2012). NF-kappaB: a key role in inflammatory diseases. The Journal of clinical investigation. 107:7-11.

Tapas, A. R., Sakarkar, D. M., Kakde, R. B., 2008. Flavonoids as nutraceuticals: a review. Tropical journal of pharmaceutical research 7, 1089-1099. 
Utsumi H., Yasukawa K., Soeda T., Yamada KI., Shigemi R., Yao T., Tsuneyoshi M (2006). Noninvasive mapping of reactive oxygen species by in vivo electron spin resonance spectroscopy in indomethacin-induced gastric ulcers in rats. J. Pharmacol. Exp. Ther. 317:228-235.

Wallace JL, Keenan CM, Granger DN., 2009. Gastric ulceration induced by Nonsteroidal anti-inflammatory drugs is a neutrophil-dependent process. Am. J. Physiol. 259: G462-67.

Woo, K.J., Jeong, Y.J., Park, J.W., Kwon, T.K., 2004. Chrysin-induced apoptosis is mediated through caspase activation and Akt inactivation in U937 leukemia cells. Biochemical and biophysical research communications 325, 1215-1222.

Xiao, Z.P., Peng, Z.Y., Peng, M.J., Yan, W.B., Ouyang, Y.Z., Zhu, H.L., 2011. Flavonoids health benefits and their molecular mechanism. Mini reviews in medicinal chemistry. 11, 169-177.

Yadav SK., Adhikary B., Chand S., Maity B., Bandyopadhyay SK., Chattopadhyay S. (2012) Molecular mechanism of indomethacin-induced gastropathy. Free Radic. Biol. Med. 52 1175-1187.

Zelickson MS, Bronder CM, Johnson BL, Camunas JA, Smith DE, Rawlinson D, Von S, Stone HH, Taylor SM., 2011. Helicobacter pylori is not the predominant etiology for peptic ulcers requiring operation. Am. Surg. 77: 10541060

التأثيرات الوقائية المحتملة لمركب كريسين على اعتلال المعدة المحدث تجريبياً في الجرذان

للسادة الاككاترة

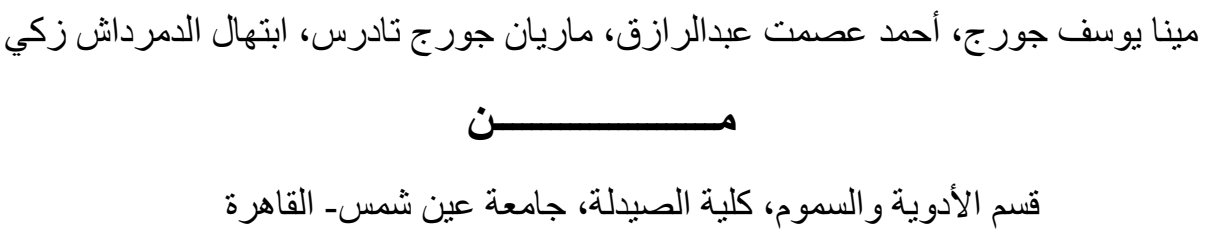

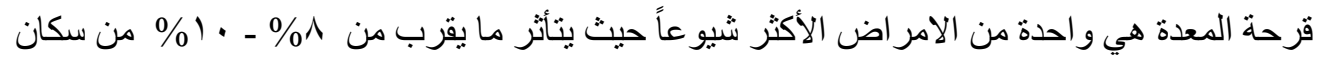

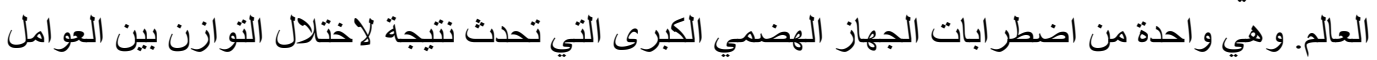

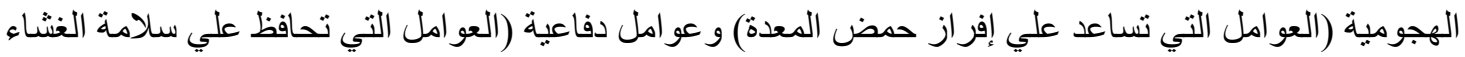

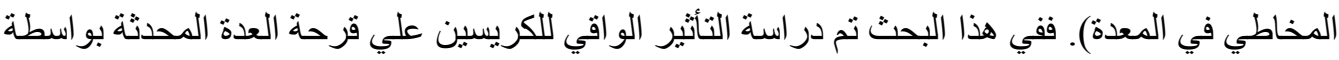

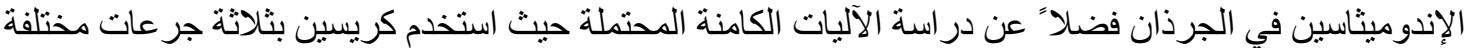

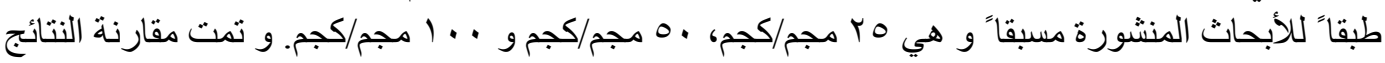

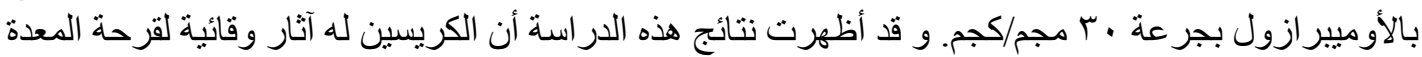

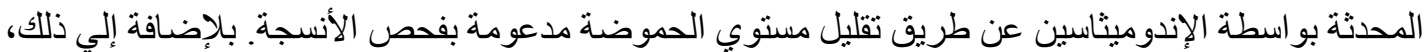

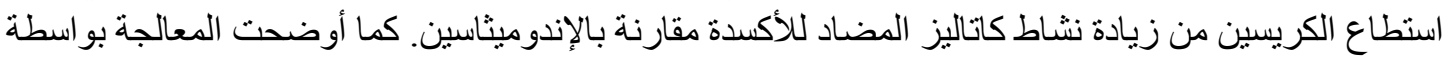

الكريسين أنه تم إثباط مؤشرات الإلتهاب المسبية بواسطة القرحة المحدثة بالإندو ميثاسين و هي عامل نخر الورم-

ألفا. 